\title{
Hiperparatiroidismo asociado a la enfermedad renal crónica
}

\section{Hyperparathyroidism and chronic kidney disease}

\author{
Ver artículo: página 136 \\ Dra. Martha Patricia Rodríguez- \\ Sánchez: Especialista en Medicina \\ Interna y Nefrología. Profesora \\ Asistente, Pontificia Universidad \\ Javeriana, Departamento de Me- \\ dicina - Hospital Universitario San \\ Ignacio. Jefe Servicio de Nefrología \\ Clínica de Marly. Presidenta Capí- \\ tulo Central 2018-2020 Asociación \\ Colombiana de Medicina Interna. \\ Bogotá, D.C. (Colombia). \\ E-mail: mprs566@gmail.com
}

\author{
El hiperparatiroidismo terciario (HPTT) se
} caracteriza por hipercalcemia en respuesta a la excesiva secreción de hormona paratiroidea (PTH) en pacientes con hiperparatiroidismo secundario (HPTS) que responden de manera ineficaz al tratamiento médico, o como consecuencia de un mal control del metabolismo fosfo-cálcico que ocasiona estimulación prolongada de las células paratiroideas, hiperplasia y con frecuencia formación de un adenoma glandular. El HPTT puede manifestarse con prurito, dolores óseos, calcificación de tejidos blandos y alteraciones bioquímicas, en especial aumento de los niveles de calcio, fósforo y fosfatasa alcalina. Esta alteración puede darse en pacientes con enfermedad renal crónica en diálisis (ERCD) o en pacientes que han recibido un trasplante renal; en este último escenario, puede persistir una excesiva secreción de PTH por la hipertrofia de las glándulas paratiroides; sin embargo, la secreción hormonal en esta población remite hasta en $90 \%$ de los casos después de 6 meses de realizado el trasplante (1).

El hiperparatiroidismo desde el punto de vista de la etiopatogenia se clasifica en hiperparatiroidismo primario, secundario y terciario $(1,2)$. El hiperparatiroidismo primario tiene su origen en las glándulas paratiroides, por lo general ante la presencia de adenoma paratiroideo con función renal normal.El HPTS es de origen extraglandular, con frecuencia por mala absorción intestinal o ERC, el calcio en estos pacientes puede ser normal o bajo y se presenta en la población renal en diálisis hasta en $92 \%$ de casos (2, $3)$ y en $2-8 \%$ de los pacientes con trasplante renal (4). El HPTT, ocurre en pacientes con largo tiempo de ERC debido a mal control metabólico durante la diálisis o después del trasplante renal como resultado de HPTS en fase de cronicidad, cursa con hipercalcemia y en ocasiones hiperfosfatemia (4). Es factible que algunos pacientes logren respuesta farmacológica con el uso de calcimiméticos orales (cinacalcet) o endovenosos como lo demuestran algunos reportes recientes de la literatura. La elegibilidad de los pacientes que requieren paratiroidectomía sigue siendo un tema controversial en algunos escenarios clínicos (5). El tratamiento quirúrgico se plantea cuando las complicaciones asociadas al exceso de PTH son muy severas, como es el caso de pacientes muy sintomáticos o con calcifilaxis, o para aquellos casos de refractariedad al manejo médico; sin embargo, como bien lo documentan en el estudio descriptivo, retrospectivo realizado por la doctora Sanint y colaboradores (6), en el que se incluyeron 32 pacientes llevados a paratiroidectomía, la cirugía puede ser la opción más viable cuando la decisión se basa en criterios clínicos, marcadores bioquímicos, hallazgos imagenológicos de adenoma glandular o hiperplasia de paratiroides y refractariedad al tratamiento. Conocer las dosis de los medicamentos recibidos y el tiempo de uso de los mismos previo a la paratiroidectomía podría ser un parámetro útil al momento de definir refractariedad al tratamiento. La mayor parte de pacientes incluidos en el estudio tenían ERC estado 5 , en diálisis con largo tiempo de evolución de la enfermedad, similar a lo reportado en diferentes estudios de la literatura (5), lo cual pudo haber impactado en la pobre respuesta farmacológica obtenida, debido a los cambios histológicos presentes en las glándulas paratiroides de estos pacientes y por otro lado, el uso de medicamentos de menor eficacia para el control del HPTS hace parte de la pobre respuesta al tratamiento médico y la progresión a una indicación quirúrgica (5). La población de pacientes trasplantados en este estudio fue muy baja y aunque es un resultado esperable, la decisión de llevar a cirugía depende en parte del tiempo de evolución del HPTT posterior al trasplante y de los hallazgos encontrados en las imágenes diagnósticas. En el estudio de Sanint y cols (6), bien describen que la mejoría del HPTS en el post trasplante suele iniciar a partir del sexto mes y puede ser variable en el tiempo, según el contexto clínico de cada paciente y de la severidad del mismo. Además, de la presencia de adenoma 
o hiperplasia de paratiroides responsables de la secreción autónoma de PTH; esta última sería la verdadera indicación quirúrgica en pacientes trasplantados, como lo sugieren estudios más recientes (7).

Si bien, en el estudio de Sanint (6) describen que se realizó autotrasplante, hubiera sido valioso conocer su localización, dado que diferentes estudios han documentado una buena correlación entre los hallazgos de los marcadores bioquímicos y el sitio de la toma de la muestras de laboratorio con respecto a los valores de PTH $(4,8,9)$; por otro lado, resultaría interesante conocer el resultado de patología, debido a que se ha observado una alta asociación entre los hallazgos histopatológicos, el comportamiento clínico y la refractariedad al tratamiento.

HPTS o HPTT, siendo dos enfermedades que tienen una fisiopatología y un comportamiento clínico diferentes, se analizan e investigan de manera conjunta puesto que ambas se ven asociadas a la ERC y constituyen la minoría de los pacientes tratados con paratiroidectomía, en especial casos de HPTS; la presencia de hiperplasia o adenomas de las glándulas paratiroides tienen indicación quirúrgica y pueden estar presentes en pacientes con HPT secundario o terciario $(4,8)$.

El estudio de Sanint y cols (6), documento niveles de calcio y fósforo más elevados en el preoperatorio, siendo más lento el descenso de fósforo en el postoperatorio con respecto al calcio después de tres meses de la cirugía; sin embargo, la disminución progresiva de estos electrolitos después de la paratiroidectomía es uno de los resultados esperados. En el estudio de Dahiana Pulgar y cols, los pacientes con HPTS tenían valores preoperatorios de fósforo y PTH significativamente más elevados, que los pacientes con HPTT y los niveles de calcemia prequirúrgica más baja de forma significativa, hallazgo concordante con otros reportes de la literatura (8).

En otras publicaciones, el estudio preoperatorio basado en imágenes es controversial en pacientes con ERC e hiperparatiroidismo (9). En un metaanálisis realizado por Caldarella y colaboradores (10), publicado en el año 2012, se analizaron 24 estudios con un total de 471 pacientes que tenían diagnóstico de HPTS a quienes les realizó cintigrama paratiroideo para detectar hiperplasia de glándulas paratiroides y encontraron que las imágenes obtenidas sugerían hallazgos compatibles con indicación quirúrgica absoluta, con una sensibilidad para encontrar hiperplasia glandular de $58 \%$ (52-65\%) y una especificidad de $93 \%$ con un IC de 95\% (10). Ellos sugieren que las imágenes prequirúrgicas tendrían indicación absoluta en casos de reintervención por persistencia o recidiva del hiperparatiroidismo asociado a ERC, debido a la alta probabilidad de presentar tejido paratiroideo residual funcionante o glándulas ectópicas donde la intervención sería más dirigida gracias a la identificación del tejido residual por cintigrama de paratiroides $(10,12)$. En el estudio de Sanint (6), se incluyeron pacientes con hallazgos ecográficos compatibles con hiperplasia de glándulas paratiroides; sin embargo, no conocemos el porcentaje de pacientes a quienes se les realizó paratiroidectomía por adenoma o hiperplasia glandular y no se incluyó la gammagrafía de paratiroides dentro de las variables del estudio, análisis que habría sido de utilidad para establecer diferencias desde el punto de vista del comportamiento clínico postoperatorio. La complicación más frecuente en pacientes llevados a paratiroidectomía es la hipocalcemia, usualmente sintomática $(9$, 10), en el estudio de Sanint (6) encontraron $28 \%$ de casos, dato cercano a lo reportado en otros estudios donde oscila entre 20 y $26 \%$ (8), esta complicación disminuye con el uso de calcio y calcitriol dos a tres días antes de la cirugía, independiente de los niveles de calcio que tenga el paciente para ese momento.

Respecto a la evolución postrasplante renal después de paratiroidectomía, estudios han demostrado que en el postrasplante inmediato como en el tardío, existe alta incidencia de manifestaciones clínicas, en especial hipofosfatemia, hipercalcemia, osteopenia y con menor frecuencia necrosis avascular de cadera, hallazgos independientes de la funcionalidad del injerto renal (13).

La enfermedad mineral ósea en el enfermo renal condiciona alto riesgo cardiovascular, riesgo de fracturas, calcificaciones extraesqueléticas y alteraciones bioquímicas y el trasplante renal permite mejoría de los niveles de PTH, calcio y fósforo desde el periodo temprano del trasplante $(9,11,13)$ y es un efecto sostenido en el tiempo. siendo esta una excelente estrategia de tratamiento en pacientes con HPTT refractario al tratamiento médico, excepto en condiciones en las cuales se documente presencia de glándulas ectópicas, tejido remanente post paratiroidectomía 
o adenoma de glándulas paratiroides que son condiciones que tienen clara indicación quirúrgica (13).

La revisión realizada por Sanint y cols (6), es muy interesante y aporta información de utilidad para los nefrólogos, sería importante que este grupo a futuro generará un nuevo documento que brinde información sobre porcentaje de recaídas post paratiroidectomía, resultados histopatológicos y darnos a conocer su opinión respecto al uso de la gammagrafía de paratiroides en pacientes con hiperparatiroidismo secundario y terciario en el contexto de ERC.

\section{Referencias}

1. Fraser WD. Hyperparathyroidism. Lancet 2009; 374 (9684): 145-58.

2. Marx SJ. Hyperparathyroid and hypoparathyroid disorders. $N$ Engl J Med 2000; 343 (25): 1863-75.

3. Marcocci C, Cetani F. Clinical practice. Primary hyperparathyroidism. N Engl J Med 2011; 365 (25): 2389-97.

4. Kilgo MS, Pirsch JD, Warner TF, Starling JR. Tertiary hyperparathyroidism after renal transplantation: surgical strategy. Surgery 1998; 124 (4): 677-83; discussion 83-4.

5. Madorin C, Owen RP, Fraser WD, Pellitteri PK, Radbill
B, Rinaldo A, et al. The surgical management of renal hyperparathyroidism. Eur Arch Otorhinolaryngol 2012; 269 (6): $1565-76$

6. Sanint V, Restrepo CA, Chala AI. Experiencia con partiroidectomía quirúrgica en pacientes con enfermedad renal crónica e hiperparatiroidismo primario. Acta Med Colomb 2018; 43: 136-41.

7. Meng C, Martins P, Frazao J,Pestana M. Parathyroidectomy in Persistent Post-transplantation Hyperparathyroidism. SigleCenter Experience. Transplant Proc 2017;49(4):795-798.

8. Dahiana Pulgar B, Aquiles Jara C, Gilberto González V, Hernán González D. Tratamiento quirúrgico del hiperparatiroidismo asociado a insuficiencia renal crónica. Rev Med Chile 2015; 143: 190-196.

9. Pitt SC, Sippel RS, Chen H. Secondary and tertiary hyperparathyroidism, state of the art surgical management. Surg Clin North Am 2009; 89 (5): 1227-39.

10.Caldarella C, Treglia G, Pontecorvi A, Giordano A. Diagnostic performance of planar scintigraphy using (9)(9) mTc-MIBI in patients with secondary hyperparathyroidism: a meta-analysis. Ann Nucl Med 2012; 26 (10): 794-803.

11. Lai EC, Ching AS, Leong HT. Secondary and tertiary hyperparathyroidism: role of preoperative localization. ANZ J Surg 2007; 77 (10): 880-2.

12. Hsieh TM, Sun CK, Chen YT, Chou FF. Total parathyroidectomy versus subtotal parathyroidectomy in the treatment of tertiary hyperparathyroidism. Am Surg 2012; 78 (5):600-6.

13. M.P Rodríguez, A. Caicedo, M.A Huérfano, P.K García, F. Berrío, D. Rosselli. Secondary hyperparathyroidism after renal Transplantation. Experience of a transplant center. Acta Med Colomb 2016; 41 (2). 